\title{
Quality of life of obstetrics fistula patients before and after surgical repair in the Jimma University Medical Center, Southwest Ethiopia
}

\author{
Tilahun Fufa Debela ${ }^{1 *}$, Zerihun Asefa Hordofa $^{2}$, Aster Berhe Aregawi ${ }^{3}$ and Demisew Amenu Sori ${ }^{4}$
}

\begin{abstract}
Background: The consequences of obstetric fistula on affected women are more than the medical condition. It has extensive physical, psychological, social, and economic consequences on them. Obstetric fistula affects the entire health and entire life of women. Women suffering from obstetric fistula are often abandoned by her partner, relatives, and the community. This study aimed to determine the quality of life of obstetrics fistula patients before and after surgical repair.

Methods: Institutional-based prospective, before and after study design was conducted in the Jimma University Medical Center from November 1, 2019-October 30, 2020. A face-to-face interview was conducted with fistula patients who visited Jimma University Medical center, fistula clinic during the study period. All fistula patients were included in the study. Accordingly, 78 women who underwent surgical repair were interviewed. The means and the standard deviation were computed using conventional statistics formulas. The unpaired t-test was used to compare two independent means, and one-way analysis of variance (ANOVA) was used to compare the quality of life before repair and after a successful repair. Linear regression analysis was done for identifying determinants of quality of life. A $P$ value of 0.05 will be considered statistical significance.
\end{abstract}

Result: The overall quality of life of women was $58.17 \pm 7.2$ before the surgical repair and $71.20 \pm 10.79$ after surgical repair. The result indicates there is a significant difference in the mean value of pre and post-operative $(P<0.001)$. The overall satisfaction of women with their health status before the surgical repair was $22.5 \pm 1.30$ and it has increased to $53.0 \pm .90$ after surgical repair. The physical health dimension score was $16.51 \pm 5.27$ before the surgical repair while it has increased to $21.77 \pm 5.38$ after the surgical repair. The score of the social domain before the surgical repair was $5.19 \pm 1.34$ and it has increased to $7.13 \pm 3.67$ after the surgical repair. The score of the environmental health domain was $17.41 \pm 2.89$ before the surgery while it also increased to $21.65 \pm 4.04$ after the surgical repair. The results have shown there was a significant difference in the mean values of pre and post-operatives in both social and environmental scores $(P<0.001)$. The score of the psychological health domain before the surgery was $19.06 \pm 1.46$ and it was increased to $19.84 \pm 3.21$ after the surgical repair. The result showed there is a significant difference in mean value pre and post-operative $(P=0.048)$, though it is a slight improvement compared to other domains.

\footnotetext{
*Correspondence: tilahunfufa@gmail.com

${ }^{1}$ Department of Health Policy and Management, Faculty of Public Health,

Jimma University, Jimma, Ethiopia

Full list of author information is available at the end of the article
} original author(s) and the source, provide a link to the Creative Commons licence, and indicate if changes were made. The images or other third party material in this article are included in the article's Creative Commons licence, unless indicated otherwise in a credit line to the material. If material is not included in the article's Creative Commons licence and your intended use is not permitted by statutory regulation or exceeds the permitted use, you will need to obtain permission directly from the copyright holder. To view a copy of this licence, visit http://creativecommons.org/licenses/by/4.0/. The Creative Commons Public Domain Dedication waiver (http://creativeco mmons.org/publicdomain/zero/1.0/) applies to the data made available in this article, unless otherwise stated in a credit line to the data. 
Conclusion: The overall quality of life of the patient with fistula was improved after successful surgical repair. Although all domains of quality of life had shown significant improvement after successful surgical repair, the psychological domain showed slight improvement.

Keywords: Fistula, Obstetric, Quality of life, Preoperative, Postoperative, Jimma

\section{Background}

Globally, more than 2 million women are living with obstetric fistula [1]. In Sub Sahara Africa, obstetric fistula is estimated that 1.60 cases per 1000 women of reproductive age, and in South Asia the prevalence is estimated at 1.20 fistula cases per 1000 reproductive age women [2]. Obstetric fistula is a serious and devastating complication of childbirth affecting millions of women in the world, especially the developing world.

An obstetric fistula refers to an abnormal opening between a woman's genital tract and her urinary tract or rectum produced by obstetric causes, usually prolonged and obstructed labor [3]. Fistula affects usually women from rural areas, who are poor, uneducated women and often with early first pregnancy [4]. Unfortunately, women who endure such obstructed labors and resulting incontinence are often young, undernourished, and married early [5]. The obstetric fistula is one of the most common and certainly most dreaded injuries [5]. The impact of fistula in a country where maternal mortality rates are high is countless [6].

Obstetric fistula has an extensive physical, psychological, social, and economic cost for women affected [7]. The women are left with persistent incontinence and the baby inevitably dies due to prolonged obstructed labor [8]. As a result of fistula, women can't control the flow of urine or feces or both. This may lead to abandonment by her partner, relatives, and /or detestation by the community [9]. If treatment is not given to such victimized women, the life of the women and her family fall in danger [4]. Several women are divorced or abandoned by their husbands, turned back by friends, and even by health professionals [10].

Obstetric fistula is not only devastating the physical health of women but emotionally and socially. Fistula is a massive psychological disturbance [11]. It leads to severe sociocultural stigmatization. In developing countries, obstetric fistula is always linked to prolonged labor and poorly performed abortion [4]. The Ethiopian health system suffers from the burden of other public health issues like malaria, HIV/AIDS, and tuberculosis breakdown [12]. This may put many women at risk. Our Hospitals suffer from shortages of supply and manpower especially highly skilled professionals who can do the surgical repair for women with obstetric fistula [13]. There is also low institutional delivery in the country, in which women give birth in their home [14]. The other challenge related to the fistula is the lack of information. Most women do not know as there is a treatment for fistula [15]. They hide their circumstances and be ill within silence [11]. Besides, the treatment of fistula is among the type of expensive treatment. The treatment center needs a laboratory, radiology, and blood bank before conducting the surgery to know patient history [15]. After surgery, it is needed post-operative wards, anesthetic services, psychological and social integration [3]. The cost of salary, single used medical equipment, and other infrastructure, together endow with huge economic loads to treat fistula [16].

In Ethiopia, there are limited numbers of hospitals that give treatment, rehabilitation, and reintegration services for obstetric fistula. Jimma University Medical Center is one of the hospitals that provide surgical repair for patients with obstetric fistula. The center supports women after surgically treated, for at least three months. The program assumes women who underwent operational repair would become comfortable with their life after treatment and would be reintegrated back to society with better confidence and self-esteem. So that the medical center provided surgical repair for several women since the service started. But, there is a paucity of information regarding the quality of life of women before and after the surgical repair. Hence, this study aimed to compare the pre-operative quality of life with that of the postoperative quality of life following successful repair of genitourinary fistula among fistula patients in the Jimma University Medical Center. The finding of this study helps the hospital managers and policymakers to consider during their planning and execution to improve the service.

\section{Methods}

\section{Study area and design}

An institutional-based prospective, before and after study design was employed in Jimma University Medical Centre; Jimma zone, from November 1, 2019, to October 30, 2020. The Medical Center is found in Jimma town. Jimma town is located $352 \mathrm{~km}$ in the Southwest of Addis Ababa, the capital. The Medical Center has a catchment population of 15 million people. It has an annual out-patient caseload of 160,000 and 106 patients had undergone fistula surgery in the last year. The Jimma University Medical Center provides services to diverse populations of three regional states; namely, Oromia, Southern Nations, 
Nationalities and Peoples, and Gambella regional states as well as for those belonging to a neighboring country like South Sudan.

\section{Study participants}

All women who visited Jimma University Medical Center and presented with complaints of continuous leakage of urine per vagina following obstetric or gynecological procedures and undergone surgical repair were included in the study. Women who were seriously ill or unable to respond during the time of data collection and women with another type of fistula, such as recto-vaginal fistula, malignant fistula, radiation fistula, and/or patients with co-morbidities affecting the quality of life were excluded from the study.

\section{Sample size and sampling techniques}

A convenient sampling technique was employed. All fistula patients, who underwent genitourinary surgical fistula repair, were included in the study. A total of 89 women with obstetric fistula were registered for surgery and provided informed consent to participate in the study. Of them,78women were completed the interview at three months. The rest of the registered were unable to complete the interview due to certain reasons. Some of them were referred to other hospitals while others left the center before three months. Women who presented with complaints of continuous leakage of urine following obstetric or gynecological procedures who were admitted to Jimma University Medical Center and eligible for genitourinary surgery were identified. Women were interviewed before the surgical intervention and three months later following the successful fistula repair.

\section{Data collection methods and tools}

Data were collected through face-to-face interviews using a structured questionnaire. The pretested data collection instrument was adopted from the World Health Organization WHOQOL-BREF questionnaire and related relevant literature $[5,7,16-18]$. The questionnaire prepared in English was translated into the regional language Afan Oromo and retranslated back into English to ensure its consistency by the language experts. The questionnaire consists of three parts. The first part evaluates the socio-demographic characteristics; the second part evaluates the patient's subjective assessment of her quality of life and satisfaction with their state of health, while the third part assesses the four domains: physical health, psychological, social health, and environmental health. Except for the socio-demographic characteristics, all parts of the questionnaire present several questions with a five-point Likert scale for the respondent to score. All women were interviewed two times before and following the successful surgical fistula repair. Two trained diploma graduated health professionals who speak the local language were collected the data. Data collectors were trained for one day to be familiar with the data collection tool. Editing and sorting of the interview questionnaire were done to determine the completeness and consistency of data every day during the data collection.

\section{Data analysis}

After data collection, each questionnaire was checked for completeness. Data were coded and entered into EpiData software version 3.1 and then exported to IBM SPSS version 21 for analysis. The results were presented in mean \pm standard deviation (SD) and percentages. The unpaired $\mathrm{t}$-test was used to compare two independent means to compare more than two independent means. The one-sample $t$-test was used to compare the variables in the preoperative and postoperative periods. Linear regression analysis was done for identifying determinants of the quality of life of obstetric fistula. The $P$ value $<0.05$ was considered statistically significant.

\section{Brief description of surgical method}

Once the results of these preliminary investigations are available the treatment options, detail of the operation and post operative period and the possible long term squeal were explained to the woman and her husband or her families where possible. Woman and her husband/ family were counseled to enable consideration of the various options before a decision can made. Informed consent for the procedure obtained and formally recorded if woman agrees to operation. Woman decides and gives her consent freely by herself. Workers in fistula clinic facilitate for admission process to hospital and the supportive care required for women awaiting surgery. Surgical techniques are employed. After the operative procedures, care is given in the fistula clinic that is mostly responsible for providing such care. Those who undergone fistula surgery need bed rest for up to 90 days after surgery depending on the type of operation and the surgeons own preference.

\section{Measurement}

We used the WHOQOL-BREF questionnaire, a 25 items abbreviated version derived from WHOQOL Bref-100 to measure fistula patient-participants quality of life [20]. This tool generates four domains such as physical health, psychological, social relationships, and environmental health. The item scores range from 1 to 5 , with a higher score indicating high quality. The domain scores were transformed into a linear scale ranging between 0 and 100 following the scoring guidelines. A mean score of less than 50 in each domain denotes poor, 50-75 indicates 
moderate, and greater than 75 indicates good quality of life $[6,8]$. Physical health was assessed by seven questions with five-point Likert scales ranging from not at all (5) to an extreme amount (1). This scale was found to have high internal consistency (Cronbach's alpha $=0.832$ ). These items were physical pain, the need for medical treatment to function daily work, having enough energy to work, able to get around, satisfaction with sleep, ability to perform the living activity, and satisfaction with the capacity to work. The psychological domain was measured by six items with five points Likert scale. This scale was found to have high internal consistency (Cronbach's alpha $=0.791$ ). These items were how much they enjoy life, having a meaningful life, their ability to concentrate, satisfaction with themself, and having negative feelings. Social domain was measured by three items with fivepoint Likert scales. The scale had high internal consistency (Cronbach's alpha $=0.765$ ). These questions were the support of friends, personal relation, and satisfaction with the living place. Similarly, the environmental domain was measure by seven questions with five-point Likert scales ranging from very satisfied (5) to very dissatisfied (1). These questions were the safety of life, health of the physical environment, having enough money, having the information they need, opportunity for leisure activity, satisfaction with access to health and transport. The prevalence of overall quality of life was calculated by the percent-mean formula: actual value minus potential minimum divided by potential maximum minus potential minimum $[19,21]$.

\section{Result}

During the last year (12 months) of the study, 89 women had their obstetric fistula surgery repair at Jimma University Medical Center. Of them, 78 women had given informed consent and were completed the study.

\section{Socio-demographic characteristics}

A total of 78 women with obstetric fistula were interviewed. Thirty-nine $(50 \%)$ of respondents belonged in the age of $20-24$ years while 18 (23.1\%) were in the age group of greater than 35 years. The mean $( \pm S D)$ age of the respondents was $27.23 \pm(7.48)$ years. Thirty-five (44.9\%) of respondents were divorced while 19 (24.4\%) of the study participants were living in separation from their husband as a result of fistula. Regarding religion, three fourth $(66.7 \%)$ of study participants were Muslim while $21(26.9 \%)$ of respondents were orthodox in religion. More than half (56.4\%) of respondents were Oromo in ethnicity and followed by Kafficho (28.2\%). A majority $(78.2 \%)$ of study participants were housewives in occupations. Of the study participants, 53(59.4\%) were unable to read and write. The age at first marriage for a majority (70.5\%) of respondents was in the age group of 15-19 years while also the age at first pregnancy for the majority (69.2\%) was in the age group of 15-19 years. Fifty-four $(69.2 \%)$ of respondents had given birth in the health facilities. Of the study participants, 47 (60.3\%) of respondents had a history of the previous stillbirth at least once. The majority (87.2\%) of study participants have no own income. Three fourth (74.4\%) of the study participants had no history of antenatal care follow-up. More than half $(53.8 \%)$ of respondents had given birth by SVD. The median duration of current labor was $39 \mathrm{~h}$ (Table 1).

\section{Quality of life}

The mean and standard deviation of the overall quality of life of women before the surgical repair was $58.175 \pm 7.2$ before the surgical repair while it has increased to71.20 \pm 10.79 after the surgical repair. The difference was highly statistically significant $(P<0.001)$. Similarly, the overall satisfaction with the health status of women before the surgical repair was $22.5 \pm 1.30$ and it has increased to $53.0 \pm 0.90$ after surgical repair of women with obstetric fistula. The difference was also statistically significant $(P<0.001)$.

Regarding the physical domains of quality of life before and after the surgical repair, the physical health score was $16.51 \pm 5.27$ before the surgical repair and it has increased to $21.77 \pm 5.38$ after the surgical repair. The result showed, statistically there is a significant difference in the mean value of pre and post-operative $(P=0.000)$. The psychological health score was $19.06 \pm 1.46$ before the surgical repair while it was increased to $19.84 \pm 3.21$ after the operation done for the women. The result also showed, statistically there is a significant difference in the mean value of pre and post-operative surgery $(P=0.048)$. The domain of social and environmental health scores has shown a significant change after the surgical procedure. The mean score of the social domain was $5.19 \pm 1.34$ before the surgical repair while it was increased to $7.13 \pm 3.67$ after the surgical repair. The result showed there is a significant statistical difference in the mean value of preoperative and postoperative. The mean score of the environmental domain was $17.41 \pm 2.89$ before the surgical repair while it was increased to $21.65 \pm 4.04$ after the surgical repair. The result showed there is a significant difference in the mean value of pre-operative and post-operative $(P=0.000)$ (Table 2$)$.

\section{Predictors of quality of life score}

All variables of quality of life were entered into a linear regression model and identified factors associated with quality of life. The model explains $38.2 \%$ of the variance (R square $=0.382, P<001)$. From all predictors: age at first 
Table 1 Sociodemographic characteristics of respondents before and after surgical repair in Jimma medical center, 2020

\begin{tabular}{|c|c|c|}
\hline Characteristics & Frequency & Percentage \\
\hline \multicolumn{3}{|l|}{ Age in years } \\
\hline $15-19$ & 4 & 5.1 \\
\hline $20-24$ & 39 & 50.0 \\
\hline $25-29$ & 15 & 19.2 \\
\hline $30-34$ & 2 & 2.6 \\
\hline Greater than 35 & 18 & 23.1 \\
\hline \multicolumn{3}{|l|}{ Marital status } \\
\hline Married & 13 & 16.7 \\
\hline Divorced & 35 & 44.9 \\
\hline Widowed & 11 & 14.1 \\
\hline Separated & 19 & 24.4 \\
\hline \multicolumn{3}{|l|}{ Religion } \\
\hline Orthodox & 21 & 26.9 \\
\hline Muslim & 52 & 66.7 \\
\hline Protestant & 5 & 6.4 \\
\hline \multicolumn{3}{|l|}{ Ethnicity } \\
\hline Oromo & 44 & 56.4 \\
\hline Amhara & 3 & 3.8 \\
\hline Kafficho & 22 & 28.2 \\
\hline Benchimaji & 9 & 11.5 \\
\hline \multicolumn{3}{|l|}{ Occupation } \\
\hline Housewife & 61 & 78.2 \\
\hline Farmer & 5 & 6.4 \\
\hline Day laborer & 2 & 2.6 \\
\hline other & 10 & 12.8 \\
\hline \multicolumn{3}{|l|}{ Educational status } \\
\hline Unable to read and write & 53 & 67.9 \\
\hline Read and write & 11 & 14.1 \\
\hline Primary (1-8) & 12 & 15.4 \\
\hline secondary and above & 2 & 2.6 \\
\hline \multicolumn{3}{|l|}{ Age at first marriage } \\
\hline $15-19$ & 55 & 70.5 \\
\hline $20-24$ & 16 & 20.5 \\
\hline $25-29$ & 7 & 9.0 \\
\hline \multicolumn{3}{|l|}{ Age at first pregnancy } \\
\hline $15-19$ & 54 & 69.2 \\
\hline $20-24$ & 18 & 23.1 \\
\hline $25-29$ & 6 & 6.6 \\
\hline \multicolumn{3}{|l|}{ Place of current delivery } \\
\hline Health facility & 54 & 69.2 \\
\hline Home & 24 & 30.8 \\
\hline \multicolumn{3}{|l|}{ Previous stillbirth } \\
\hline No & 15 & 19.2 \\
\hline Once & 47 & 60.3 \\
\hline$>2$ Times & 16 & 20.5 \\
\hline \multicolumn{3}{|l|}{ Having their income } \\
\hline Yes & 10 & 12.8 \\
\hline No & 68 & 87.2 \\
\hline
\end{tabular}

Table 1 (continued)

\begin{tabular}{lll}
\hline Characteristics & Frequency & Percentage \\
\hline History of PNC follow-up & & \\
Yes & 20 & 25.6 \\
No & 58 & 74.4 \\
Mode of delivery & & \\
SVD & 42 & 53.8 \\
C/S & 11 & 14.1 \\
Instrumental delivery & 25 & 32.1 \\
\hline
\end{tabular}

marriage, satisfaction with support from friends, satisfaction with themselves, satisfaction with a capacity to work, able to concentrate, and satisfaction with the personal relationship were statistically significant factors associated with the quality of life.

Holding other variables constant, the age at first marriage was directly related to the quality of life. As the age at first marriage increased one unit, the quality of life increased by $1.522[\beta=1.522,(95 \% \mathrm{CI}: 0.471,2.573)]$. Women who underwent surgical repair had 4.552 units more satisfaction with the support from their friends than before undergoing surgical repair $[\beta=4.552,(95 \% \mathrm{CI}: 3.338,5.766)]$. Women who underwent surgical repair had 3.57 units more satisfaction with themselves than before undergoing surgical repair $[\beta=3.57,(95 \% \mathrm{CI}: 2.413,4.727)]$. As women undergo a surgical repair, the satisfaction of women in their capacity to work certain activities had increased by 3.868 units $[\beta=3.868,(95 \%$ CI: $2.668,5.067)]$. As a woman with obstetric fistula gets surgical repair, the ability of women to concentrate on certain things had increased by 3.187 units $(\beta=3.187,(95 \% \mathrm{CI}$ : $1.560,4.814))$. Surgical repair of a fistula increases the satisfaction of the personal relationship of women. As a woman undergo surgical repair, the satisfaction with her relationship had increased by 4.137 units $[\beta=3.187$, (95\% CI: 2.986, 5.288)]. The social score was directly related to the quality of life $(\beta=1.908)$, that is as a woman underwent a surgical repair, the social aspect of a woman had increased by 1.908 (95\% CI: 1.400, 2.417)). Similarly, the psychological and physical health dimension score was directly related to the quality of life, that is as the psychological score increased a unit quality of life score increased by 2.584 [ $\beta=2.584$, (95\% CI: $2.062,3.106)]$. As physical health increased a unit quality of life increased by 1.824 [ $\beta=1.824,(95 \%$ CI: 1.570, 2.079)] (Table 3).

\section{Discussion}

Following the surgical repair, there is an improvement in the overall quality of life by $13 \%$ and the overall satisfaction to their health was improved by $50 \%$. This result was in line with a study done in India in which the overall 
Table 2 Quality of life of respondents before and after surgical repair in Jimma medical center, 2020

\begin{tabular}{|c|c|c|c|c|c|c|c|c|}
\hline & \multirow[t]{2}{*}{ Before } & \multirow[t]{2}{*}{ After } & \multirow[t]{2}{*}{$\mathbf{t}$} & \multirow[t]{2}{*}{ df } & \multirow[t]{2}{*}{ Sig. (2-tailed) } & \multirow[t]{2}{*}{ Mean difference } & \multicolumn{2}{|c|}{$\begin{array}{l}95 \% \text { confidence } \\
\text { interval of the } \\
\text { difference }\end{array}$} \\
\hline & & & & & & & Lower & Upper \\
\hline \multicolumn{9}{|l|}{ One-sample test } \\
\hline Physical health & $16.51 \pm 5.27$ & $21.77 \pm 5.38$ & 8.529 & 75 & 0.000 & 5.26632 & 4.0363 & 6.4964 \\
\hline Psychological & $19.06 \pm 1.46$ & $19.84 \pm 3.21$ & 2.016 & 68 & 0.048 & .78058 & 0.0080 & 1.5531 \\
\hline Social & $5.19 \pm 1.34$ & $7.13 \pm 3.67$ & 4.611 & 75 & 0.000 & 1.94158 & 1.1027 & 2.7804 \\
\hline Environmental & $17.41 \pm 2.34$ & $21.65 \pm 4.04$ & 9.155 & 75 & 0.000 & 4.24789 & 3.3236 & 5.1722 \\
\hline Overall satisfaction & $22.5 \pm 1.30$ & $53.0 \pm .90$ & 7.458 & 66 & 0.000 & 1.250 & 2.896 & 2.166 \\
\hline The overall quality of life & $58.17 \pm 7.2$ & $71.20 \pm 10.79$ & 10.033 & 68 & 0.000 & 13.03290 & 10.4408 & 15.6250 \\
\hline
\end{tabular}

Table 3 Logistic regression analysis about factors associated with quality of life among fistula patients undergone surgical repair, South West Ethiopia, 2020

\begin{tabular}{|c|c|c|c|c|c|c|c|}
\hline \multirow[t]{2}{*}{ Model } & \multicolumn{2}{|c|}{$\begin{array}{l}\text { Unstandardized } \\
\text { coefficients }\end{array}$} & \multirow{2}{*}{$\begin{array}{l}\text { Standardized } \\
\text { coefficients } \\
\text { Beta }\end{array}$} & \multirow[t]{2}{*}{$\mathbf{t}$} & \multirow[t]{2}{*}{ Sig } & \multicolumn{2}{|c|}{$95.0 \%$ confidence interval for $B$} \\
\hline & B & SE & & & & Lower Bound & Upper Bound \\
\hline (Constant) & 48.175 & 7.546 & & 6.384 & 0.000 & 33.112 & 63.237 \\
\hline Age at first marriage & 1.522 & 0.527 & 0.333 & 2.891 & 0.005 & 0.471 & 2.573 \\
\hline Unable to read and write & 1 & & & & & & \\
\hline Read and write & 0.160 & 1.415 & 0.014 & 0.113 & 0.910 & -2.664 & 2.985 \\
\hline Formal education & 2.014 & 1.349 & 0.179 & 1.493 & 0.140 & -0.678 & 4.706 \\
\hline Need medical treatment to function daily life & 1.119 & 0.990 & 0.137 & 1.130 & 0.263 & -0.858 & 3.096 \\
\hline Enjoying life & -0.349 & 1.061 & -0.040 & -0.329 & 0.743 & -2.466 & 1.769 \\
\hline Satisfaction with support from a friend & 4.552 & 0.608 & 0.675 & 7.484 & 0.000 & 3.338 & 5.766 \\
\hline Satisfaction with your self & 3.570 & 0.580 & 0.6011 & 6.159 & 0.000 & 2.413 & 4.727 \\
\hline Satisfaction with your capacity to work & 3.868 & 0.601 & 0.618 & 6.436 & 0.000 & 2.668 & 5.067 \\
\hline Able to concentrate & 3.187 & 0.815 & 0.431 & 3.909 & 0.000 & 1.560 & 4.814 \\
\hline Satisfaction with the personal relationship & 4.137 & 0.577 & 0.659 & 7.175 & 0.000 & 2.986 & 5.288 \\
\hline Social health dimension score after & 1.908 & 0.255 & 0.675 & 7.486 & 0.000 & 1.400 & 2.417 \\
\hline Psychological dimension score after & 2.584 & 0.261 & 0.770 & 9.883 & 0.000 & 2.062 & 3.106 \\
\hline Physical health dimension score after & 1.824 & 0.127 & 0.868 & 14.309 & 0.000 & 1.570 & 2.079 \\
\hline
\end{tabular}

${ }^{a}$ Dependent variable: overall quality of life

quality improvement by $85 \%$ following the surgical repair [6]. In our case, the project only gives medical services to fistula patients. In another part of fistula centers, social and psychological integration have given in addition to medical services. This might be the reason why there is a slight improvement. From the domains of quality of life psychological domain was not showed large improvement after surgical repair. Before the surgery, the quality of life was 19.06 while it was 19.84 after surgical repair. A substantial portion of women was not satisfied with their relations, the support they get from their friends, and the condition of their living places which confirms the occurrence of psychological trauma on women. From the environmental health domains, the majority of women have no money to meet their needs, able to get enough information in their daily life, and have no opportunity for leisure activities. The possible explanation for this might be women faced poor support. In this regard, Jimma University medical center provides some financial support, but this support is not enough for them. Primarily, women with fistula need assistance from husband, family, and community members. On contrary, they divorced because of the fistula and become psychologically ill, and lack the necessary support. In our study, about $45 \%$ of women had divorced and about $24 \%$ were living separated from their husbands as a result of fistula. The majority of women who participated in this study were illiterate. Education has a direct relationship 
with awareness. It has been known that lack of awareness affects the health-seeking behavior of women. In this study, the majority of women married and got pregnant in the age group of 15-19, which may indicate the prevalence of early marriage in the country which contributes a lot to the incidence of fistula. Early pregnancy and home delivery expose women to the risk of fistula [10]. Obstructed labor contributes high to the case of fistula. In this study, the majority of women who were with obstetric fistula and participated in this study gave birth at their home. Place of delivery was a significant factor associated with the problem encounter during the delivery [22].

In our study, there is a significant change in the physical health domain among women who underwent surgical repair at Jimma University Medical Center $(P<001)$. This result is explained by the fact that relief from physical pain, physical improvement, satisfaction with their sleep, and their day-to-day work. This result is in line with a study done in India, Nigeria, and another part of the country $[6,15,19]$. Similarly, the social health domain showed significant improvement after a woman gets a surgical repair. Rejection from their husband, friends, families and feeling dissatisfied in their condition of the living place was the manifestation of social impacts. Statistically, there is a significant improvement in the social domain after the surgical procedure $(P<0.001)$. The result of the present study is in line with the study done in other parts of the world in which surgical repair improves the social aspect of women $[6,8,15,19]$.

\section{Conclusion}

In conclusion, the overall quality of life was improved after successful surgical repair. All domains of quality of life have shown significant improvement after the surgical repairs. The psychological related factors showed litthe improvement compared to other domains. Physical health and social health dimensions showed more change than other dimensions. Quality of life was influenced by satisfaction with support from friends, the capacity to work, and the ability to concentrate to do certain activities. It is recommended that the medical center and other concerned parties should implement psychological and social rehabilitation and reintegration mechanisms in addition to medical interventions to improve the quality of life of women with fistula.

\section{Acknowledgements}

We are grateful to acknowledge our data collectors for collecting the data carefully and the study participants for providing the necessary information.

\section{Authors' contributions}

Both TFD and ZAH are involved in the study proposal writing, design, data analysis, write-up, and ABA and DAS are involved in the conception of the idea. All authors have reviewed and approved the submission of the manuscript.

\section{Funding}

The data collection process of this study was funded by the Jimma University for the support of the data collection. The funding body only followed the process to confirm whether the fund allocated was used for the proposed research.

\section{Availability of data and materials}

The data collected for this study can be obtained from the first author based on a reasonable request at the email: tilahunfufa@gmail.com.

\section{Declarations}

\section{Ethics approval and consent to participate}

Ethical clearance was obtained from the Institutional Review Board (IRB) of the Jimma University Institute of Health with reference number of IRB/218/12. A permission letter was obtained from the Department of Gynecology and obstetrics department of Jimma University and submitted to Jimma University Medical Center. Informed consent was taken from each participant before the start of data collection. All information obtained from participants was kept with confidentiality. Besides, they were told they have the right not to participate and withdraw from the study at any time. All experiment protocol of this study was done in accordance with the declaration of Helsinki and approved by the linstitutional review board (IRB) of the Jimma University of Ethiopia.

\section{Consent form}

I have been informed about this study's purpose, procedures, possible benefits and risks, and the use and disclosure of my child's health care information from this research. I have read and understood this consent form, and have been given the opportunity to ask any questions I may have. All my questions have been answered to my satisfaction. I freely give my consent for my child to participate in this research study. I authorize the use and disclosure of my child's health information to the parties listed in the authorization section of this consent for the purposes described above. By signing this consent form I have not waived any of the legal rights to which my child is otherwise entitled.

\section{Consent for publication}

Not applicable.

\section{Competing interests}

The authors declare that they have no competing interests.

\section{Author details}

${ }^{1}$ Department of Health Policy and Management, Faculty of Public Health, Jimma University, Jimma, Ethiopia. ${ }^{2}$ Maternal Health Project Coordinator at Jimma University, Jimma, Ethiopia. ${ }^{3}$ Program Analyst, Midwifery United Nations Population Fund, Addis Ababa, Ethiopia. ${ }^{4}$ Department of Obstetrics and Gynecology, Jimma University, Jimma, Ethiopia.

Received: 8 December 2020 Accepted: 7 May 2021

Published online: 21 May 2021

\section{References}

1. Polan ML, Sleemi A, Bedane MM, et al. Obstetric fistula. In: Debas HT, Donkor P, Gawande A, et al., editors. Essential Surgery: Disease Control Priorities. 3rd ed. vol. 1. Washington (DC): The International Bank for Reconstruction and Development / The World Bank; 2015. Chapter 6. Available from: https://www.ncbi.nlm.nih.gov/books/NBK333495/. https://doi.org/ 10.1596/978-1-4648-0346-8 ch6.

2. Sung VW, Rogers RG, Barber MD, Clark MA. Conceptual framework for patient-important treatment outcomes for pelvic organ prolapse. Neurourol Urodyn. 2014;33(4):414-9.

3. De Ridder D, Badlani GH, Browning A, et al. Fistulas in the developing world. In: Abrams P, Cardozo L, Khoury S, Wein A, editors. Incontinence. 4th ed. Paris, UK: Health Publications Ltd; 2009. p. 1419-58. 
4. El AAM, Barageine J, Korn A, Kakaire O, Turan J, Obore S, et al. Trajectories of women's physical and psychosocial health following obstetric fistula repair in Uganda: a longitudinal study. Trop Med Int Health. 2019;24(1):53-64.

5. Rgelancu G. Obstetric fistula. World Health Organization; 2016. p. 231-47.

6. Singh V, Jhanwar A, Mehrotra S, Paul S, Sinha RJ. A comparison of quality of life before and after successful repair of genitourinary fistula: is there improvement across all the domains of. Afr J Urol. 2015;21(4):230-4. https://doi.org/10.1016/j.afju.2015.06.003.

7. Nusee Z, Rusly A, Jamalludin AR, Abdulwahab DF, Ismail R. Translation and validation of Bahasa Malaysia version of urogenital distress inventory (UDI-6) and incontinence impact quality of life questionnaires (IIQ-7), a cross-sectional study. Malays J Med Sci. 2016;23(3):57-63.

8. Chipungu E, Moyo M, Wilkinson J. Continence, quality of life and depression following surgical repair of obstetric vesicovaginal fistula: a cohort study. BJOG. 2019;126:926-34

9. Singh V, Jhanwar A, Mehrotra S, Paul S, Sinha RJ. A comparison of quality of life before and after successful repair of genitourinary fistula: is there improvement across all the domains of the WHOQOL-BREF questionnaire? Afr J Urol. 2015;21(4):230-4. https://doi.org/10.1016/j.afju.2015.06. 003.

10. Meurice M, Genadry R, Heimer C, Ruffer G. Social experiences of women with obstetric fistula seeking treatment in Kampala, Uganda. Ann Glob Health. 2017:83(3-4):541-9. https://doi.org/10.1016/j.aogh.2017.07.003.

11. Ahmed S, Holtz SA. Social and economic consequences of obstetric fistula: life changed forever? Int J Gynaecol Obstet. 2007;99:510-5.

12. LaForgia GM, Sulvetta MB, Lewis MA. Public hospital costs and quality in the Dominican Republic. World Bank, Policy Res Work Pap Ser 934, 1992. 1992. http://search.proquest.com/docview/56608852?accountid= 14701\%0Ahttp://sfx.scholarsportal.info/ottawa?url_ver=Z39.88-2004\& rft_val fmt=info:ofi/fmt:kev:mtx:journal\&genre=preprint\&sid=ProQ: ProQ\%3Aeconlit\&atitle=Public +hospital+costs+and+quality+in+ the+Dominic.

13. FMoH of Ethiopia. Health Sector Development Programme IV 2010/112014/15. Heal Sect Dev Program IV. 2014 (October 2010)
14. CSA I. Ethiopia Demographic and Health Survey 2016 key indicators report, vol. 49. 2016

15. Matiwos B. Quality of life and associated factors among women with obstetric fistula in Ethiopia. Res Square. 2020; https://doi.org/10.21203/ rs.3.rs-51612/v1.

16. Egziabher TG, Eugene N, Ben K, Fredrick K. Obstetric fistula management and predictors of successful closure among women attending a public tertiary hospital in Rwanda: a retrospective review of records. BMC Res Notes. 2015;8:1-7.

17. Ficheur G, Caron A, Beuscart J, Ferret L, Jung Y, Garabedian C, et al. Casecrossover study to examine the change in postpartum risk of pulmonary embolism over time. BMC Pregnancy Childbirth. 2017;17:1-7.

18. Jayarajah U, Wickramasinghe DP, Samarasekera DN. Anal incontinence and quality of life following operative treatment of simple cryptoglandular fistula-in-ano: a prospective study. BMC Res Notes. 2017;10:1-5.

19. Umoiyoho AJ, Inyang-etoh EC, Abah GM, Abasiattai AM, Akaiso OE. Quality of life following successful repair of vesicovaginal fistula in Nigeria. Rural Remote Health. 2011:11:1-7.

20. WHO. Introduction, administration, scoring, and generic version of the assessment field trial version December 1996 program on mental health World Health Organization. WHO; 1996.

21. Debela TF, Salgedo WB, Tsehay YE. Predictors of intention-to-leave the current job and staff turnover among selected health professionals in Ethiopia. Glob J Manag Bus Res 2017:17(2).

22. Assefa L, Alemayehu M, Debie A. Magnitude of institutional delivery service utilization and associated factors among women in the pastoral community of Awash Fentale district Afar Regional State, Ethiopia. BMC Res Notes. 2018;11(1):4-9. https://doi.org/10.1186/s13104-018-3261-5.

\section{Publisher's Note}

Springer Nature remains neutral with regard to jurisdictional claims in published maps and institutional affiliations.
Ready to submit your research? Choose BMC and benefit from:

- fast, convenient online submission

- thorough peer review by experienced researchers in your field

- rapid publication on acceptance

- support for research data, including large and complex data types

- gold Open Access which fosters wider collaboration and increased citations

- maximum visibility for your research: over $100 \mathrm{M}$ website views per year

At BMC, research is always in progress.

Learn more biomedcentral.com/submissions 